\title{
The key issues when choosing adaptation of an existing building over new build
}

Received (in revised form): 20th October, 2008

\section{Paul Watson}

is Professor of Building Engineering and Head of Construction, Cost and Surveying at Sheffield Hallam University. Paul's experience is varied, having spent some years in the construction industry as a project manager where he gained practical knowledge before entering the world of academia. Paul has not lost his industrial roots and he has written numerous publications on construction and surveying related topics including authoring and co-authoring eight textbooks that have practical application. He has also designed degree courses that specifically address the requirements of building engineers and surveyors.

Correspondence: Paul Watson, Faculty of Development \& Society, Sheffield Hallam University, Owen Building, Howard Street, Sheffield S1 1WB, UK; Tel: +44114225 5555; Fax: +44 1142253179

\begin{abstract}
The current restrictions on the flow of credit facilities for house purchases and investment funds for new commercial developments caused by the 'credit crunch' have severely impacted upon the UK housing and commercial building markets. House starts and completions have more or less come to a full stop and very few new commercial projects have commenced. The demand for houses/ homes, however, has not diminished; people still require accommodation at a price that they can afford, also there is still a demand for some commercial infrastructure facilities. This paper explores a viable alternative for combating the decline in new house and commercial completions by builders. The rationale for a trend move towards an increased use of adaptations along with the associated advocated advantages is provided. Further the identification of the key issues to be addressed when considering and engaging in the adaptation of buildings are presented and explained.
\end{abstract}

Journal of Building Appraisal (2009) 4, 215-223. doi:10.1057/jba.2008.39

\section{Keywords:}

adaptation, conversion, decision making, extension, refurbishment

\section{INTRODUCTION}

The problematic issues facing the United Kingdom with regard to construction are numerous; many of them are direct consequences of previous decisions made by construction industry professionals, their clients and financial institutions. These problems include the following:

- House purchase credit facilities: Gaining entry onto the housing ownership ladder is becoming increasingly difficult for many sectors of society.

- A lack of investment funds for commercial development projects.

- Population size and demographics - increasing population size and changing demographics: The population is increasing and it is also growing older. In addition the expected number of households are increasing at a disproportionate rate to population growth. 
- Density of population: The United Kingdom has one of the highest densities of population in Europe that puts unsustainable pressure on the countryside and limited natural resources.

- Brownfield development: There is a restriction on 'Greenfield' construction with a government target of 60 per cent of new work to be on Brownfield sites.

- Environmental impact of buildings: There is an unsustainable environmental footprint emanating from the millions of existing buildings as well as the vast majority of new buildings built each year, although this has decreased considerably in relation to housing.

The construction industry and the buildings it produces, maintains, repairs, converts and demolishes have both an immediate and long-term impact upon our environment. This paper will consider the use of adaptations as a means of addressing some, if not all of the problematic issues facing the UK population and construction industry. The rationale for advocating this approach is to try and ensure that clients are provided with viable alternatives to new build projects, it is part of the surveyor's role to provide such alternatives and in today's economic climate new build is not always the optimum solution.

\section{BROWNFIELD DEVELOPMENT}

In 2000, the UK Government introduced Planning Policy Guidance 3: Housing (PPG3) and in this document the government set out a target for the increased use of Brownfield sites. This was done to promote the 'greening' of the government and to address public fears about the growth in urban sprawl. There were, and are, many hectares of derelict land left empty as a result of the loss of major heavy and manufacturing industries, along with many inner city areas that are in desperate need of regeneration. Development of such sites was seen as an obvious way forward, but it could only provide part of the solution to the demands of the UK housing and commercial market sectors.

The target set by the government was to achieve 60 per cent of new housing development on Brownfield sites by 2008. The definition of Brownfield sites was subsequently altered to include refurbishment work and the new Planning Policy Statement 3: Housing (PPS3) that replaces the PPG3 and does not use the term 'Brownfield' but instead uses the term 'previously used'. The term used in PPS3 (2000) 'includes land and buildings that are vacant or derelict as well as land that is currently in use but which has potential for re-development'. Annex B of the PPS3 (2000) adds the following definition; 'Previously-developed land is that which is or was occupied by a permanent structure, including the curtilage of the developed land and any associated fixed surface infrastructure'.

The rate of new homes built on Brownfield sites varied from 53 per cent in 1991 to 59 per cent in 1999 and the average for the ten years up to the target being set was 56 per cent. The inclusion of refurbishment works in PPG3 added approximately 3 percentage points, so the target set was not particularly difficult to achieve. Some commentators, such as Lord Rogers, have called for the Brownfield target to be raised considerably and regionally targeted for example 100 per cent Brownfield development in the North and Midlands. The reutilisation of existing land and buildings is sometimes a viable alternative to new more expensive building projects, especially considering the shortage of finance in these areas, which is very likely to get worse over the next few years? 


\section{DENSITY POPULATION}

This is obviously a factor of both size of population as well as area of land. The United Kingdom, with a density of 246 people per square kilometre, is third in a comparison of densities across European countries - this, however, hides the fact that the density across the various countries that make up the United Kingdom vary considerably. According to the National Statistics Online (2005)

\section{'Scotland is the least densely populated of the four countries of the UK. There were 65 people resident per square kilometre .... in 2003. In comparison the population density was 125 people per square kilometre in Northern Ireland, 142 people in Wales and 383 people in England'.}

If the density of the population of England is considered alone against other European countries, it comes a very close second to the Netherlands that has a density of 392 people per square kilometre. Italy, France, Spain and Norway have by comparison densities of 193, 110, 85 and 12 people per square kilometre, respectively (see Figure 1).

Such a high level of density puts a heavy demand on our countryside and its limited natural resources. The result of this when coupled with a shortage in the supply of houses, means there is increasing pressure to release green belt and other 'open' spaces for development to ease the strain on the housing and commercial market. The problem here for a country that prides itself on its 'green and pleasant land' is that according to the Department for Environment and Rural Affairs (2000), between 1990 and 1998 there was an increase of 5 per cent in built-up rural areas and urban sprawl. Making better use of existing buildings could assist in alleviating this situation.

\section{ADAPTATION}

There are various definitions of the term adaptation and one of the best is provided by Chudley as cited by Douglas (2002), 'In general terms adaptation means the process of adjustment and alteration of a structure or building and/or its environment to fit or suit new conditions'. To this Douglas (2002) added 'it is also considered as work accommodating change in use or size or performance of a building which may include alterations, extensions, improvements, and other works modifying it in some way'.

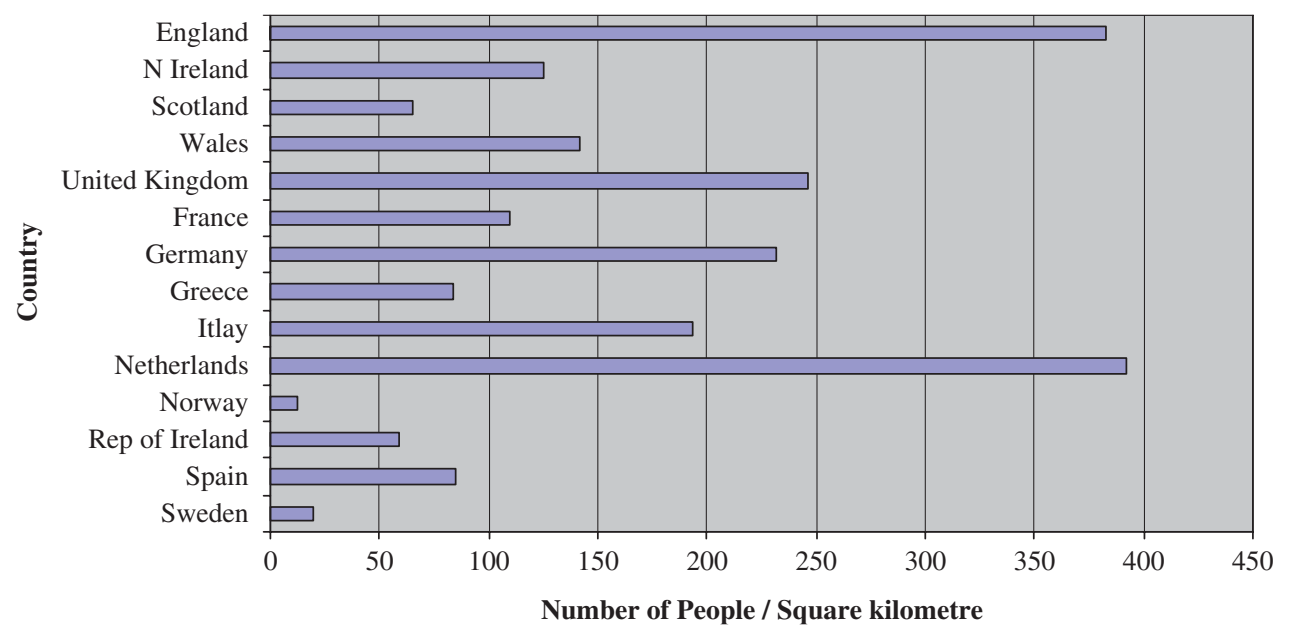

Figure I: Density of population for sample of European countries (data obtained from National Statistics Online, 2005) 
There are three main forms of adaptation namely:

- Conversion: work including a change in function or change in use, such as converting an office block and making it suitable for residential use;

- Extension: work that includes an increase in size, which can be horizontal or vertical expansion;

- Refurbishment: work that is related to a change in performance.

There are, however, in addition to the three listed above, many other terms that would come under the general umbrella description of adaptation. These terms include:

- Alteration (remodelling): A change in formation, that is removal of partition walls to enlarge a space within the fabric of a building, or conversely the introduction of partition walls to subdivide a space into smaller units.

- Conservation (restoration): Preservation of the existing building and its fabric and fittings, in their current state, for the future. Restoration implies a degree of repair to bring fabric, components or fittings back to an acceptable standard.

- Modernisation (rehabilitation): An upgrade in an element or elements of a building. A suitable example here would be the installation of a new central heating system with appropriate controls and zoning, to an older property.

- Maintenance: Repair and/or replacement work to keep or restore any/every part of a building, to current standard(s).

The above are sometimes valid alternatives to new build, but may not be fully considered by the surveyor and/or client.

One of the reasons for the lack of clarity and overlapping of the various terms highlighted above is that the terms are often used by construction professionals to describe the main adaptation work being carried out on a building. Owing to the nature of a project, however, the work required may also include some elements covered by other terms. Thus an office building being changed into residential use will obviously be a conversion but the work undertaken within the contract will undoubtedly include, some alterations to internal walls, possibly a horizontal extension and probably a modernisation of the external envelope to bring it into line with current regulations.

There are many reports on the benefits of adapting an existing building compared to demolishing it, clearing the site and then constructing a new building on that site. Many of these are produced by the Chartered Institute of Building (CIOB) in their Construction Papers series. One such paper titled 'Built Asset Management: Refurbishment and Optimum Land Use' developed a series of 'factors favouring refurbishment'. These included the following:

- Social factors: energy and/or resource conservation, preservation of historic buildings and social resistance to change;

- Economic factors: shorter construction periods, a desire to keep a business running, condition of building, planning constraints, insufficient funds, need to upgrade a building, expectation of high land values, uncertain long-term value, loss of investment, unwillingness of neighbours to develop and constraints on development.

To give the subject matter a balanced view, the paper also contained factors that may make refurbishment less desirable. These were called 'Limiting Factors' and contained 
the following: diminishing returns, suitability for reuse, marketable features, life expectancy, occupancy cost, high cost of borrowing, outdated facilities, management of refurbishment, cost of providing safety, security etc (Kwayke, 1994).

Many of these limiting factors were explored in more detail in subsequent research and a further CIOB paper identified 33 characteristics of refurbishment work, which were ranked by managers of such projects. The results established that cost control was the main problematic issue and this was closely followed by variations and pricing of tenders. In addition control of dust and noise were ranked highly on the list of issues (Egbu, 1996).

While it is accepted that by the very nature of adaptation work, 'surprises' are more likely to occur than on Greenfield work, as they will be discovered only as the project proceeds. It should be made clear that for any significant adaptation work a feasibility study is essential to avoid many of the problems, namely variations and cost control, identified by the sampled managers above.

A Construction Industry Research and Information Association (CIRIA) Report entitled A Guide to the Management of Building Refurbishment (1994) makes it clear that there is a need to research the existing building and that this is a major task. The report also emphasises that this 'discovery' phase (feasibility study) has to be given sufficient time, early enough in the project, so that the design, procurement and construction can be properly based on the feasibility study's findings.

Many studies illustrate the acknowledged benefits of adaptation, whether it is a conversion and/or refurbishment. These benefits include an increased speed of construction and even when time is used to carry out a feasibility study the total project duration can be up to 50 per cent less for refurbishment/adaptation projects compared with new build. The reasons for this are many fold and include the fact that adaptation projects are generally less susceptible to delays from inclement weather on site as the external envelope and the roof covering will usually be in place when work commences. If instead of a refurbishment the existing building is demolished, with the resulting waste removed from site and new materials having to be delivered, it can be appreciated that there will be less disruption to neighbouring buildings and neighbours from the refurbishment option, and apart from the reduction in cost from landfill alone, there are likely to be fewer holdups with material deliveries as much of the required materials will already be present.

Another key benefit of adaptation over demolition and new build is that the costs are usually lower, assuming a thorough feasibility study has been carried out, easier to forecast and control. As the project duration will usually be shorter any borrowing or loss of earnings on capital employed by the client will also be less. There are usually savings to be made on site security and other associated site establishment and running costs.

Having addressed the constraints set by time and finance, it should be mentioned that there are other increasingly important issues to be considered. These include a smaller environmental impact of the adaptation due to: less vehicle movements, less materials having to be put into landfill, reduced utilisation of new materials and their associated embodied energy use/costs; and the preservation of our built heritage. It is assumed that if the building was listed then demolition and rebuild would not be an option, but many older buildings, although not listed, are important visually and some people would argue that they have far better architectural merit than some new buildings erected today.

\section{ESTABLISHING CLIENT REQUIREMENTS}

When considering a client's requirements, which may commence with a request for a new structure, the surveyor should be prepared to consider any viable alternatives and present 
such alternatives to the client. The total cost associated with a building project will be a combination of the following (Ferry and Brandon, 1984):

(a) cost of land;

(b) legal etc ... costs of acquiring and preparing the site;

(c) demolition or other physical preparation of the site;

(d) building costs;

(e) professional fees in connection with last;

(f) furnishings, fittings, machinery etc;

(g) costs in connection with disposal (sale, letting etc) where the building is to be disposed of at completion;

(h) cost of financing the project (this principally represents interest etc, on the money expended before any return is obtained either by way of income or of use);

(i) cost of management, running and maintenance where the building is to let to a tenant but the owner has made himself responsible for some or all of these costs.

The true mix of the costs associated with a structure will of course depend upon the type of structure and its location. The surveyor's task should be to provide the client with a building that will meet their needs and keep to a minimum the total cost package. Therefore, some formal evaluation and decision-making process has to be deployed by the surveyor.

Figure 2 depicts a suitable decision-making model and within the model the following stages can be identified:

- Defining the problem: This stage is concerned with clarifying the specific details of the problem by drawing the boundaries of the decision. The scope of the decision is defined, and the decision maker's attention should be focused on what are regarded as the major aspects of the decision. In building terms this stage is concerned with clearly establishing the clients' brief and obtaining as much information as possible relating to the client's financial circumstances, this activity will require and should be allocated an adequate amount of time.

- Setting objectives: Having clearly defined the clients' requirements, it is necessary to consider what it is hoped the decision will achieve or what aims it should work towards. This aspect of the decision-making process is very much concerned with turning the clients' brief into specific objectives of what has to be achieved and within the allocated time frame, cost parameters and specification.

- Determine the options: This is a critical phase when related to the building decisionmaking process and may be partly a creative one. It is about generating alternatives that at least on the face of it can satisfy the client's requirements, and yet the resultant option(s) may not be a new build project, as they may have originally considered. Some form of 'Thought Shower' could be utilised to generate a range of alternatives and/or group discussions. The main focus is to think outside the box and try and produce viable, more suitable options, and this requires the surveyor and client to have an open mind.

- Evaluate options: This phase of the decision-making process involves determining the extent that the generated options meet the clients' requirements in the most efficient and effective manner. Therefore, the consequences of each option need to be spelt out in some considerable detail, and, some form of costing model would prove useful at this stage. This would put some quantitative data into the decision-making process, but one must not forget the value of qualitative data in such a process. 


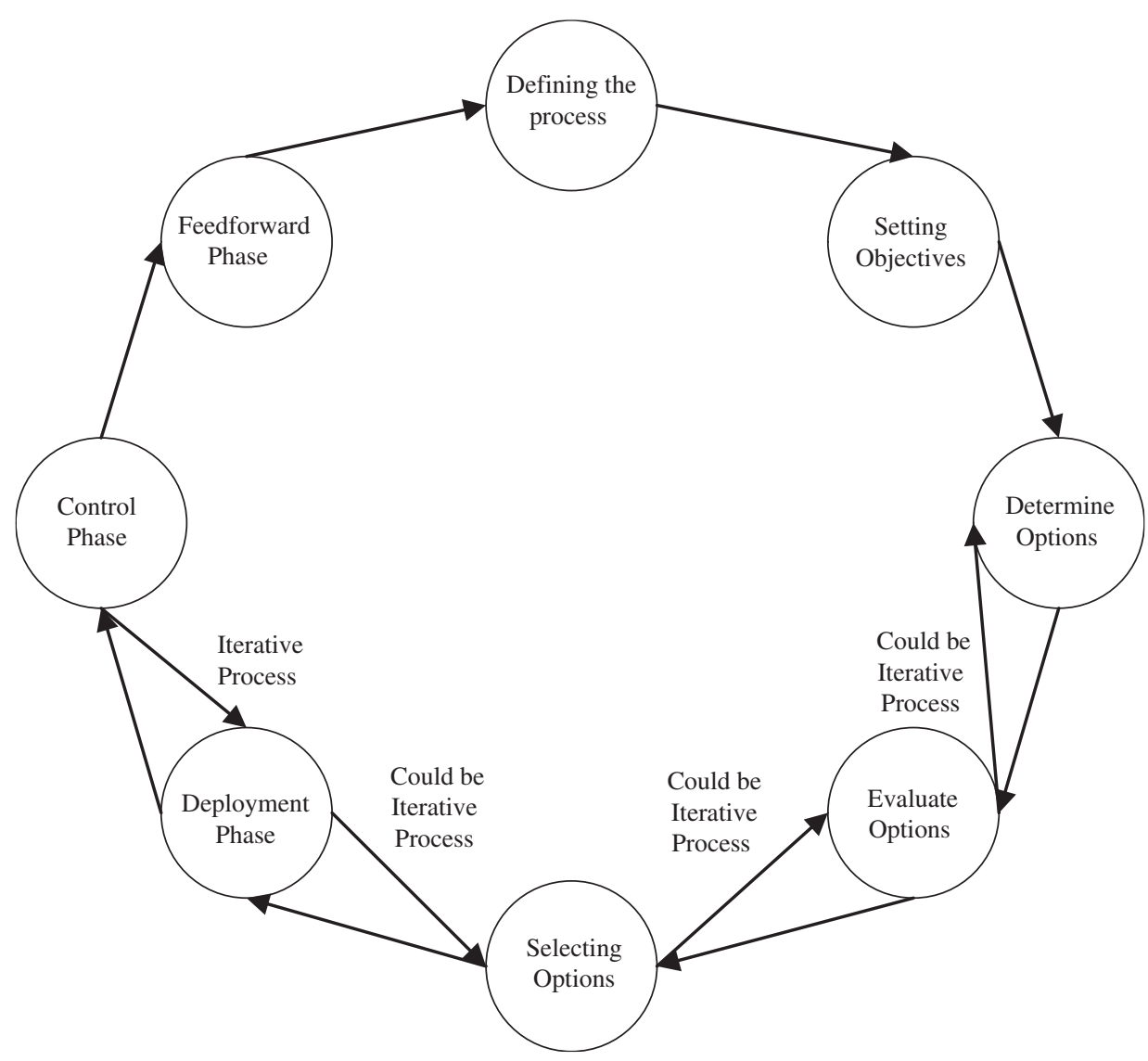

Figure 2: Decision-making model

- Selecting the option: This is the point in the decision-making process towards which the other stages have been working. It is here that one of the viable decision options is selected as being most likely, if implemented, to prove most satisfactory to the client.

- Deployment phase: If the correct decision has been taken and therefore the best option selected (and the implementational ability should be part of the decision-making criteria in option selection), the surveyor working with other professionals must develop an appropriate deployment strategy/plan. This strategy/plan will of course be set within the parameters of the clients' previously established criteria of cost, time and specifications. There also needs to be an element of flexibility (contingency planning) after all strategy is not always incremental and can be emergent.

- Control phase: During the deployment phase it is vital that activities are controlled. Control is exercised by the feedback of information upon actual performance when compared with a predetermined plan. Control is governed by cycle time (how long does it take to compare and contrast what was planned with what actually transpired) and the quality of information circulating (an appropriate level of detail is essential for tight control) within a control feedback loop.

- Feed forward phase: This final stage is concerned with feeding forward the results of the project and learning from the process. It involves a critical analysis of the entire decision-making activity, for example were the decision-making phases adhered to and conducted appropriately. Did the process lead to client satisfaction and what could have 
been done differently and improved the process and client's experience. This phase is all about taking the experience forward and learning from previous projects so that performance is improved each time and on each new project (Cook and Slack, 1984).

Should an adaptation option, however, be the result of the decision-making process then there are still critical issues to be addressed and these are noted in the next section.

\section{BUILDING ADAPTATIONS: KEY ISSUES TO BE ADDESSED}

In order that the right decisions can be taken when considering adapting a building certain issues have to be carefully considered and evaluated and these are:

- Building suitability: This relates to the size and shape of the building and requires careful examination to ensure it will meet the client's requirements.

- Building structure: This is often quite apparent from an early stage; however, the exact type in conjunction with the materials used has to be ascertained.

- Condition of building: Once the structure of the building has been considered, the next stage is to examine the building for defects, whether they are structural or surface defects.

- Aesthetics: It is unlikely for example that a 1960s office building would have an appearance of any particular architectural merit; however, this may not concern the client.

- Project brief: It is critical that the client's requirements and expectations of time, cost and suitability are examined to ensure that there is a common understanding between what the client is expecting and what can be delivered within the set parameters.

- Sustainability: The traditional driving forces of time and cost are usually the most influential; however, if both of these factors are to be maximised then due consideration needs to be given to a number of sustainable practices at a very early stage. Examples of this would be an appraisal of the condition of the existing materials that is roof covering, is it in a suitable condition so that it can all be reused or will other materials have to be found to match?

- Legal issues: It is quite likely that the adaptation of a building will involve work that requires a party wall notification. A benefit of a building adaptation is that there should be no change to the right to light of neighbours, unless an extension is planned as part of the refurbishment.

- Change of use: Where a building undergoes a change of use, the resulting building must comply with the current building regulations. This can cause significant problems and a study carried out by 'Building Magazine' found that the main areas, indicated by construction professionals (which included construction managers and building control officers), were: exclusion of moisture, thermal insulation, sound insulation, means of escape, fire protection and accessibility. These can add significant costs to the project.

\section{CONCLUSIONS}

This paper has highlighted the role that the adaptation of buildings could have in addressing the UK's housing and commercial building problems. The adaptation process must, however, take full account of the size and depth of the environmental footprint the built environment generates. To do this a feasibility study must be carried out to ensure that not only does the proposed project proceed with limited problems but also to allow a full assessment of how the building can be best upgraded, to take full advantage of both energy efficiency and other environmental improvements. When considering a building for adaptation, due consideration needs to be given to the initial costs and the future 
running costs as well as the contribution to global environmental concerns. These factors can all be incorporated into the advocated decision-making process model. A trend move towards an increased use of adaptation work would be positively correlated to a change in the professional role/workload of surveyors in the future and this may require some re-training or continuing professional development activities for surveyors.

\section{References}

Construction Industry Research and Information Association (CIRIA). (1994) Report R133 - A Guide to the Management of Building Refurbishment by J G Perry, CIRIA, London.

Cook, S. and Slack, N. (1984) Making Management Decisions, Prentice-Hall International Inc, London, UK, ISBN 0-13547837-5.

Department for Environment and Rural Affairs. (2000) Countryside Survey — Accounting for Nature: Assessing Habitats in the UK Countryside [online], available at: http://www.defra.gov.uk/wildlife-countryside/cs2000/02/01. htm Accessed February 2007.

Douglas, J. (2002) Building Adaptation, Butterworth Heineman, Oxford, ISBN 0-7506-5085-0.

Egbu, C. (1996) Characteristics and Difficulties Associated with Refurbishment. Construction Papers No. 66, CIOB, Ascot.

Ferry, D.J. and Brandon, P.S. (1984) Cost Planning of Buildings, BSP Professional Books, London, UK, ISBN 0-63202403-8.

Kwayke, A.A. (1994) Built Asset Management: Refurbishment and Optimum Land Use. Construction Papers No. 29, CIOB, Ascot.

National Statistics Online. (2005) Population — UK Population Grows to 59.6 million [online], available at: http://www. statistics.gov.uk/cci/nugget.asp?id=760 Accessed February 2007. 